\title{
Remineralization Therapies for Initial Caries Lesions
}

\author{
Bennett T. Amaechi ${ }^{1}$
}

Published online: 9 April 2015

(C) Springer International Publishing AG 2015

\begin{abstract}
This is a review of the latest scientific advances in technologies for effective management of initial (noncavitated) caries lesions. The increasing emphasis on preventive and minimal intervention dentistry coupled with the established higher prevalence of non-cavitated caries compared to cavitated tooth surfaces is encouraging nonsurgical management of early caries among the practicing dentists. Thus, there is need for effective treatment strategies to facilitate non-operative care of initial caries lesions (remineralization). The new strategies should either facilitate fluoride action, work better than or synergistically with fluoride to provide a fuller remineralization of the lesions. An overview of new developments shows encouraging number of scientifically sound therapies with promising potential to be efficacious. However, there is shortage of strong clinical evidence generated through randomized clinical trials to support the efficacy and effectiveness of these new technologies. Devices with high validity and accuracy to measure and monitor remineralization are also needed to enable clinical data collection to validate effectiveness of these therapies.
\end{abstract}

Keywords Remineralization - Self-assembling peptides . Arginine $\cdot$ SPRG $\cdot$ Bioactive glass $\cdot$ Fluoride

This article is part of the Topical Collection on Cariology

Bennett T. Amaechi

amaechi@uthscsa.edu

1 Department of Comprehensive Dentistry, University of Texas Health Science Center at San Antonio, 7703 Floyd Curl Drive, San Antonio, TX 78229-3900, USA

\section{Introduction}

Remineralization can be defined as the delivery and deposition into the caries lesion of the mineral elements, mostly calcium and phosphate, lost through demineralization of the tooth tissue. Remineralization result to growth by apposition of hydroxyapatite crystals, and if fluoride is present in the environment, fluorapatite will be formed. Remineralization is the treatment for an active initial stage (non-cavitated) caries lesion, aimed to reverse the caries lesion or arrest the progression of the lesion to cavitated stages. Successful remineralization of a lesion should start at patient level by engaging the individual in reviewing their dietary and oral hygiene behaviors, at local level by establishing and maintaining a neutral $\mathrm{pH}$ and state of supersaturation of calcium and phosphate ions on the tooth surface, and at the lesion level by prolonged mineral ions' access to the lesion body.

The importance of remineralization in dental practice cannot be overemphasized, considering the established facts that early caries lesions are more prevalent than cavitated tooth surfaces [ $[1 \cdot$, especially in children age 18 months and below [2]. With this fact, coupled with the growing interest in preventive and minimal invasive dentistry, the non-operative care of initial caries lesions (remineralization), is now one of the caries risk management elements in the recently established International Caries Classification and Management System (ICCMS $^{\mathrm{TM}}$ ) guide for caries management for Practitioners and Educators (Fig. 1), which aims to maintain health by preserv-

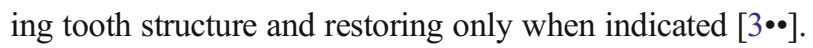

\section{When Do We Remineralize?}

The decision to remineralize an active initial caries lesion depends on the clinical stage, the radiological extent (when 
Fig. 1 Overview of ICCMS ${ }^{\mathrm{TM}}$ elements for caries management [3]

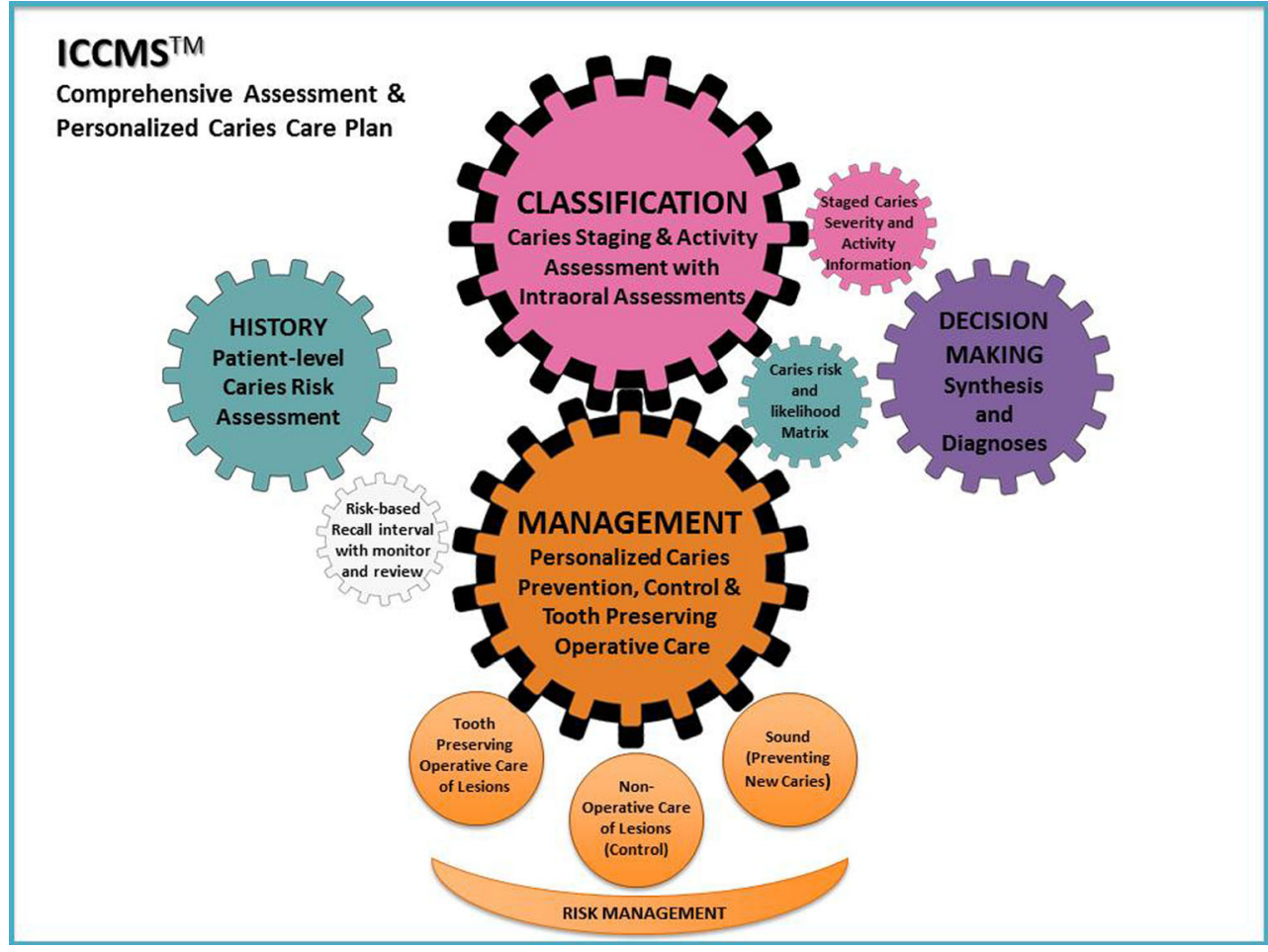

information is available) of the lesion in enamel or dentin, and the caries risk status of the patient, which determines the likelihood of the lesion progressing to cavitation (Fig. 2). Although the ICCMS ${ }^{\text {тм }}$ review of the best available evidence suggests remineralization for initial caries with radiolucency reaching the outer one-third of dentin, this recommendation can be locally modifiable as can be seen from Fig. 3 used in one of the US dental schools.

\section{Remineralization Therapies}

Caries remineralization ability of fluoride is considered to be the "gold standard" against which other remineralization systems have to compete, either alone or in combination with fluoride [4••]. Ideal remineralization material should diffuse or deliver calcium and phosphate into the lesion or boost the remineralization properties of saliva and oral reservoirs without increasing the risk of calculus formation [5•]. Fluoride is currently recognised as the main active ingredient in different fluoridated products tailored for remineralization and prevention of progression of existing caries. However, use of fluoride vehicles can reverse early lesions but most effective at the surface of the lesion [6]. This may lead to remineralization of the porous surface layer, causing the blockage of enamel pores and thereby reducing the ionic exchange activity of surface enamel and hindering the remineralization of the underlying lesion body, making full remineralization difficult to achieve [7]. This justifies the search for new treatment strategies that could either facilitate fluoride action, work better than or synergistically with fluoride to provide a fuller remineralization of lesions. An overview of latest advances in remineralization therapies that employ important nonsurgical modalities are discussed below in a way that is relevant to clinicians practicing in the community.
Fig. 2 ICCMS $^{\text {TM }}$ caries risk and likelihood matrix [3]

\begin{tabular}{|c|c|c|c|c|}
\hline & & \multicolumn{3}{|c|}{ Current Caries Activity Status at the Patient Level } \\
\hline & & $\begin{array}{l}\text { No active caries } \\
\text { lesions* }\end{array}$ & $\begin{array}{l}\text { Initial stage active } \\
\text { caries lesions }\end{array}$ & $\begin{array}{l}\text { Moderate- or } \\
\text { extensive-stage } \\
\text { active caries lesions } \\
\end{array}$ \\
\hline \multirow{3}{*}{$\begin{array}{l}\frac{n}{2} \\
\frac{\pi}{\omega} \\
\frac{\omega}{\omega} \\
\frac{\omega}{\alpha}\end{array}$} & Low risk & $\begin{array}{c}\text { Low } \\
\text { likelihood }\end{array}$ & $\begin{array}{l}\text { Moderate } \\
\text { likelihood }\end{array}$ & $\begin{array}{c}\text { Moderate } \\
\text { likelihood }^{\star}\end{array}$ \\
\hline & Moderate risk & $\begin{array}{c}\text { Low } \\
\text { likelihood } \\
\end{array}$ & $\begin{array}{l}\text { Moderate } \\
\text { likelihood }\end{array}$ & $\begin{array}{c}\text { High } \\
\text { likelihood }\end{array}$ \\
\hline & High risk & $\begin{array}{l}\text { Moderate } \\
\text { likelihood }\end{array}$ & $\begin{array}{l}\text { High } \\
\text { likelihood }\end{array}$ & $\begin{array}{l}\text { High } \\
\text { likelihood }\end{array}$ \\
\hline
\end{tabular}




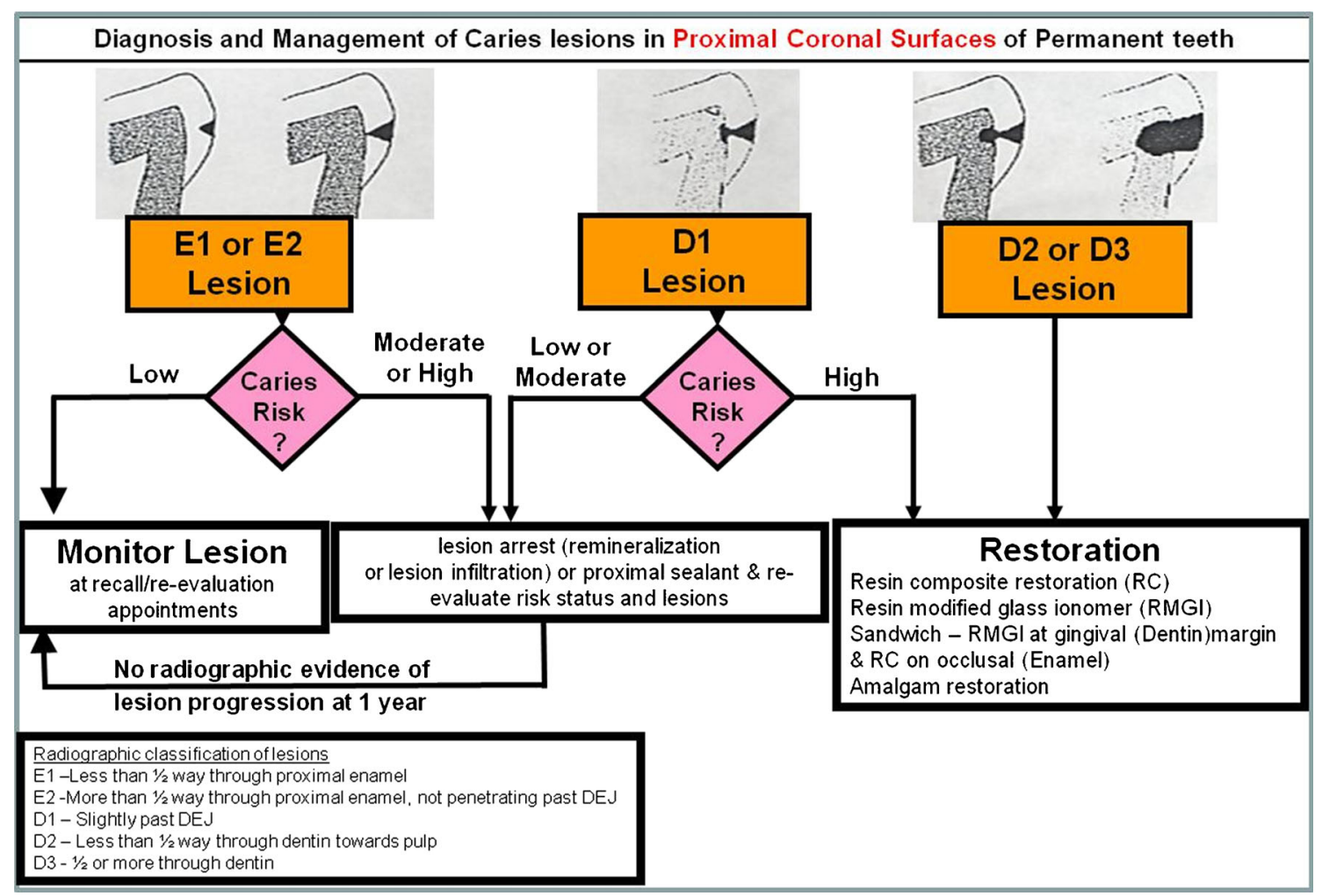

Fig. 3 Caries management decision tree based on patient's caries risk and lesion radiological extent (Courtesy: University of Texas Health Science Center at San Antonio)

\section{Acidulated Fluoride Products}

There is growing number of acidulated fluoridated products in the dental market now. Typical of such products are mouthrinse of sodium fluoride with phosphoric acid at $\mathrm{pH}$ 3.0-4.0, gels and foams. Development of these products was motivated by the following scientific facts. As stated above, one of the shortcomings of fluoride in remineralization, especially the high fluoride concentration products, is surface-zone remineralization at the expense of the lesion body, resulting in lesion arrest and not full remineralization of the lesion. However, it has been demonstrated that reducing the $\mathrm{pH}$ of the fluoridated vehicle, such as mouthrinse, gel, or varnish, may prolong the ingress of mineral ions into the lesion body by preventing the blockage of enamel pores, thus enabling full remineralization of the lesion. In addition, at a low $\mathrm{pH}$, there is release of calcium and fluoride associated with bacteria, particularly bacterial lipoteichoic acid, as well as the calciumfluoride-like and other calcium salts deposits in plaque matrix and tooth surfaces [8]. These processes would provide calcium and/or fluoride at the site of action when needed most, thus potentiating the remineralization process.

\section{Self-Assembling Peptides}

The most recent advancement in remineralization arsenal is the Curolox ${ }^{\circledR}$ Technology utilizing self-assembling peptides
(P11-4) for regenerative treatment of early caries lesions. Products containing this peptide as the active ingredient are commercially available in Europe as a monomer, Curodont ${ }^{\mathrm{TM}}$ Repair (Credentis AG, Windisch, Switzerland). In this technology, the P11-4 monomers applied to an early caries lesion, diffuse into the subsurface micropores of the lesion and assemble under high ionic strength into a 3D-matrix (scaffold), which attracts calcium phosphate from saliva and templates de novo hydroxyapatite crystal formation around the matrix, i.e., triggering biomimetic mineralization that enables the regeneration of enamel and dentin $[9,10]$. This process takes several weeks to accomplish remineralization of the treated lesion.

\section{Arginine Technology}

The amino acid, arginine, was recently incorporated into toothpaste containing $1.5 \%$ arginine, insoluble calcium carbonate, and $1450 \mathrm{ppm}$ fluoride as sodium monofluorophosphate and tailored for remineralization of early caries lesion and prevention of development of new lesions. This technology is based on the mechanism that when the toothpaste is used, the amino acids will be deaminated by the arginine deaminase (enzyme) system in saliva, producing ammonia, which is highly alkaline and causes a rise in $\mathrm{pH}$ within the oral environment, thus presenting an ideal condition for remineralization as well as modifying and reducing the pathogenicity of the cariogenic plaque [11]. With the sodium monofluorophosphate providing the 
fluoride ions and the calcium carbonate serving as the calcium source, remineralization is enhanced. Several studies have provided overwhelming evidence for efficacy of this technology. In vivo studies demonstrated that the cariogenic potential of the plaque is reduced, consistent with the significantly enhanced efficacy of the arginine-containing toothpaste in arresting and reversing caries as observed in the enamel and root caries clinical studies compared with toothpaste containing fluoride alone [11].

\section{Functionalized Tricalcium Phosphate Products}

Products containing functionalized tricalcium phosphate technology are commercially available from 3M ESPE Inc., as toothpastes, Clinpro ${ }^{\mathrm{TM}} 5000$ with 5000 ppm fluoride (USA), Clinpro tooth crème with $850-950 \mathrm{ppm}$ fluoride (Asia/Australia), and as fluoride varnishes, Clinpro ${ }^{\mathrm{TM}}$ White Varnish with 26,000 ppm fluoride (USA/Asia/Australia). This technology is tailored to enhance remineralization through better formulations and the addition of calcium to complement fluoride. In this technology, by milling $\beta$ tricalcium phosphate (TCP) with organic materials (functionalization), the calcium oxides in TCP become "protected" by the organic materials, thus allowing the calcium and phosphate ions of the TCP to coexist with fluoride ions in an aqueous dentifrice base (toothpaste or varnish) without premature TCP-fluoride interactions [12]. As the ingredient reaches the tooth surface, the organic materials (often surfactants such as fumaric acid or sodium lauryl sulfate), which have an affinity for tooth surfaces, carries the calcium to the tooth surface, protected from fluoride ion. Saliva activates the calcium compound, degrading the protective coating, releasing calcium at the tooth surface, resulting in high fluoride and calcium bioavailability on the lesion surface and subsequent diffusion into the lesion to promote remineralization. Evidence for the benefits of TCP is mounting. Placebo-controlled clinical studies have demonstrated that relative to fluoride alone, the combination of fluoride plus functionalized TCP can improve remineralization of both white-spot lesions as well as eroded enamel $[13,14]$.

\section{Surface Pre-reacted Glass-Ionomer Filler}

Surface pre-reacted glass-ionomer (SPRG) filler is the active ingredient in commercially available GIOMER products (SHOFU Inc., Kyoto, Japan), comprising of toothpastes, pits/fissure sealants, composite resins and resin barrier coat. A ligand exchange mechanism within the pre-reacted hydrogel endows the SPRG fillers with the ability to release and recharge fluoride ions [15], and as such can achieve a sustained fluoride release, which is acidity-dependent. In addition, these fillers release multiple other ions such as $\mathrm{Sr}^{2+}$, $\mathrm{Na}^{+}, \mathrm{BO}_{3}{ }^{3-}, \mathrm{Al}^{3+}$, and $\mathrm{SiO}_{3}{ }^{2-}$ at high concentrations [16] This multiple ion-releasing capacity endows resinous materials containing SPRG fillers with several therapeutic effects $[15,17]$, including the modulation of the $\mathrm{pH}$ of the surrounding medium, shifting it to neutral and weak alkaline regions [16], thus presenting an ideal condition for lesion remineralization by the released ions. Because of the released fluoride and silica, the eluate of resins filled with SPRG fillers enhances the formation of apatite in the presence of mineralizing oral fluid, such as saliva [18]. $\mathrm{Sr}^{2+}$ released from SPRG fillers may also enhance the acid resistance of teeth by converting hydroxyapatite to strontiumapatite. Clinical evidence, such as randomized clinical trials, to support the efficacy of these products for lesion remineralization is yet to be produced.

\section{Bioactive Glass Products}

The existing bioactive glass (Novamin ${ }^{\mathrm{TM}}$ ) used in commercial toothpastes, Sensodyne Repair \& Protect and Sensodyne Complete Protection (GlaxoSmithKline, UK), is the 45S5 composition, which does not contain fluoride. Rather sodium monofluorophosphate is added to the toothpaste formulation, which creates the possibility of premature reaction of calcium and fluoride to form calcium fluoride $\left(\mathrm{CaF}_{2}\right)$ that may compete with or inhibit subsequent fluoroapatite formation. Recently, innovators successfully incorporated fluoride, strontium, potassium, and zinc within the glass itself to produce fluoride-containing bioactive glass toothpaste with fluoride within the glass, thus enabling the delivery of $\mathrm{Ca}^{2+}, \mathrm{PO}_{4}{ }^{3-}$, and $\mathrm{F}^{-}$ions simultaneously in the appropriate amounts to form fluoroapatite from a single glass composition, in order to avoid the possible formation of $\mathrm{CaF}_{2}$ [19]. Originally, bioactive glasses $(\mathrm{BG})$ were added in dentifrice formulations for treating dentin hypersensitivity by forming a surface layer of hydroxycarbonate apatite on the tooth, thereby occluding exposed dentinal tubules. Fluoride-containing BG, however, was developed to serve as a remineralizing additive for dentifrices by releasing therapeutically active ions, such as strontium and fluoride for caries remineralization and prevention, zinc for bactericidal properties, and potassium as a desensitizing agent [19]. Fluoride-containing bioactive glass (f-BG) is engineered to release fluoride over a 12-h period within the oral environment. Normally, bioactive glasses react with saliva and typically form hydroxycarbonate apatite [20], enabling the remineralization of initial caries lesion; however, f-BG form fluorapatite that is more chemically stable against acid attack [21]. Although these products are already in the market, there is still need for randomized clinical trial to provide strong evidence for their effectiveness.

\section{Nanohydroxyapatite Products}

Nanohydroxyapatite-containing toothpastes and oral rinses tailored for remineralization and caries prevention are 
available from two companies, Sangi company, Tokyo, Japan, and Periproducts Ltd, Middlesex, UK. The concentration of nanohydroxyapatite (nHAP) in Sangi toothpastes (Apagard $^{\mathrm{TM}}$ ) and cream (Renamel ${ }^{\mathrm{TM}}$ ) ranges from 5-20\% depending on the targeted function, remineralization/caries prevention or dentin hypersensitivity treatment. Periproducts' toothpastes (UltraDex calcifying) and oral rinse (UltraDex daily rinse) combines nHAP and fluoride for remineralization and caries prevention or with added stabilized chlorine dioxide for whitening. Nanohydroxyapatite, a bioactive and biocompatible material, functions by directly filling up the micropores in early caries lesions, where it act as a template in the remineralization process by continuously attracting large amount of calcium and phosphate ions from the oral fluids into the lesion, thus promoting crystal growth [22]. It is pertinent to mention that when combined with fluoride in aqueous formulations such as toothpastes and rinses, nHAP lowers the bioavailable $\mathrm{F}$ concentration, with $\mathrm{NaF}$ being slightly more of a concern than sodium monofluorophosphate [23]. Evidence from clinical studies demonstrated the efficacy of the Apagard ${ }^{\mathrm{TM}}$ toothpastes in remineralizing initial caries lesions [24] and preventing caries development in school children [25]. Apagard ${ }^{\mathrm{TM}}$ toothpastes exhibited the same remineralizing ability as fluoridated toothpaste with $1500 \mathrm{ppm}$ fluoride as sodium monofluorophosphate [24]. There is not yet clinical evidence supporting the effectiveness of the UltraDex products in remineralizing early caries lesions.

\section{8 \% Silver Diamine Fluoride}

A new breed of silver diamine fluoride without the blackening (staining) effect, Riva Star (SDI Ltd, Victoria, Australia), was introduced into the dental market recently for remineralization of initial caries lesions. Although originally snubbed by its staining effect, silver diamine fluoride (SDF) has received considerable attention as a caries-preventive agent [26], and $38 \%$ SDF has been shown to be effective in arresting coronal caries [27]. In a randomized clinical study, the annual applications of SDF arrested more active initial caries and reduced more new caries formation than using $\mathrm{NaF}$ varnish every 3 months [28]. Besides arresting the progression of an existing initial caries, SDF is antimicrobial and has affinity for the mineral and organic constituents of tooth tissue.

\section{Casein Phosphopeptide Amorphous Calcium Phosphate (Recaldent ${ }^{\mathrm{TM}}$ )}

The CPP-ACP have been incorporated into sugar-free chewing gums, fluoride varnish, and dental cream (GC corporation) and is commercially available as Tooth Mouse (Asia/Australia) and MI paste (USA) and the fluoridecontaining CPP-ACFP (with 900-ppm fluoride) as Tooth
Mouse-plus and MI paste-plus and MI varnish (USA). Casein phosphopeptide (CPP) is a milk-derived phosphoprotein that stabilizes high concentrations of calcium and phosphate ions in a soluble amorphous calcium phosphate at acidic and basic $\mathrm{pH}$ as well as in the presence of fluoride ions; forming nanoclusters of casein phosphopeptide-stabilized amorphous calcium phosphate (CPP-ACP) or casein phosphopeptidestabilized amorphous calcium fluoride phosphate (CPPACFP) nanocomplexes [29]. When applied intraorally, these nanocomplexes bind onto the tooth surfaces and dental plaque to create a state of supersaturation of calcium and phosphate ions in the oral biofilm, providing high level of bioavailable calcium and phosphate ions to facilitate remineralization and modifying the dynamics of the demineralizationremineralization events when cariogenic challenge occurs, to prevent caries development [30]. The nanocomplexes has been reported to diffuse through the porosities in an early caries lesion into the body of lesion where they release the weakly bound calcium and phosphate ions, which would then deposit into crystal voids to form hydroxyapatite or in the presence of fluoride, the fluorapatite [31]. There is a lot of clinical evidence supporting the remineralizing efficacy of Recaldent ${ }^{\mathrm{TM}}$ [32].

\section{Combination of Calcium Glycerophosphate and Sodium Monofluorophosphate}

Calcium glycerophosphate is an ingredient in some brands of toothpastes and oral rinses, such as the Spry ${ }^{\mathrm{TM}}$ toothpaste and Spry ${ }^{\mathrm{TM}}$ oral rinse (Xlear, Inc., American Fork, UT, USA). Although the Xlear toothpaste and rinse contain $0.243 \%$ $(w / w)$ sodium fluoride, in a caries clinical trial of toothpaste, combining calcium glycerophosphate with sodium monofluorophosphate (SMFP) demonstrated effectiveness over SMFP alone [33]. This effectiveness is suggested to be based mainly on its ability to elevate plaque-calcium concentrations, when delivered from toothpaste [34].

\section{Theobromine}

Most recent addition to the oral hygiene arsenal is the Theodent toothpaste (Theocorp Inc., USA), with theobromine as the active ingredient. The only study on the remineralization efficacy of theobromine reported that theobromine, at a molar level 71 times less than that of fluoride, has remineralization effect comparable to that of fluoride [35]. When delivered from toothpaste, it has been suggested that its ability to induce increase in crystallite size and improve crystallinity of apatite in the presence remineralizing medium, such as saliva, is the predominant mechanism [36]. However, there is a clear need for more clinical trials to produce evidence for the efficacy of this agent for remineralization of early caries. 


\section{Conclusions}

It is obvious that the increasing emphasis on preventive and minimal intervention dentistry, which is encouraging nonsurgical management of early caries lesions among the dental practitioners, is stimulating the development of various remineralizing therapies by innovators and industry. A lot of these technologies have high potential to be efficacious; however, there is shortage of strong clinical evidence generated through randomized clinical trials to support the efficacy and effectiveness of these newly developed products. Devices with high validity and accuracy to measure and monitor remineralization are needed to enable collection of the clinical data to validate efficacy and effectiveness of these newly developed therapies.

\section{Compliance with Ethics Guidelines}

Conflict of Interest Bennett T. Amaechi declares no conflict of interest.

Human and Animal Rights and Informed Consent This article does not contain any studies with human or animal subjects performed by any of the authors.

\section{References}

Papers of particular interest, published recently, have been highlighted as:

- Of importance

- Of major importance

1. Ismail AI, Brodeur J-M, Gagnon P, Payette M, Picard D, Hamalian $\mathrm{T}$, et al. Prevalence of non-cavitated and cavitated carious lesions in a random sample of 7-9-year-old school children in Montreal, Quebec. Community Dent Oral Epidemiol. 1992;20:250-5. This manuscript is one of the early papers to bring the awareness of the early caries lesions and the importance of reversing or arresting the progression of these lesions to cavitation.

2. Mattos-Graner Rde O, Rontani RM, Gavião MB, Bocatto HA. Caries prevalence in 6-36-month-old Brazilian children. Community Dent Health. 1996;13(2):96-8.

3.• International Caries Classification and Management System (ICCMS ${ }^{\mathrm{TM}}$ ) Guide for Practitioners and Educators. file:///C:/ Users/k1467713/Desktop/www.kcl.ac.uk/sspp/kpi/projects/ healthpolicy/global-caries-management. This manuscript presents a recent consensus guide on when and how to nonsurgically manage an early caries lesion (remineralization).

4.• Zero DT. Dentifrices, mouthwashes, and remineralization/caries arrestment strategies. BMC Oral Health. 2006;6 Suppl 1:S9. This manuscript presents the first detailed strategies for remineralization of early caries.

5. Amaechi BT, van Loveren C. Fluorides and non-fluoride remineralization systems. In: van Loveren C, editor. Toothpastes. Monogr oral Sci. Basel: Karger; 2013. p. 15-26. This monograph chapter presents a compilation of most recent active ingredients in toothpaste for remineralization or arrestment of early caries.

6. Biesbrock AR, Faller RV, Bartizek RD, Court LK, McClanahan SF. Reversal of incipient and radiographic caries through the use of sodium and stannous fluoride dentifrices in a clinical trial. J Clin Dent. 1998;9:5-10.

7. ten Cate JM, Arends J. Remineralization of artificial enamel lesions in vitro: III. A study of the deposition mechanism. Caries Res. 1980;14:351-8.

8. Lynch RJ, Smith SR. Remineralization agents - new and effective or just marketing hype? Adv Dent Res. 2012;24(2):63-7. doi:10. 1177/0022034512454295. Review.

9. Kirkham J, Firth A, Vernals D, Boden N, Robinson C, Shore RC, et al. Self-assembling peptide scaffolds promote enamel remineralization. J Dent Res. 2007;86(5):426-30.

10. Brunton PA, Davies RP, Burke JL, Smith A, Aggeli A, Brookes SJ, et al. Treatment of early caries lesions using biomimetic selfassembling peptides - a clinical safety trial. Br Dent J. 2013;215(4):E6. doi:10.1038/sj.bdj. 2013.741-746.

11. ten Cate JM, Cummins D. Fluoride toothpaste containing $1.5 \%$ arginine and insoluble calcium as a new standard of care in caries prevention. J Clin Dent. 2013;24:79-87.

12. Karlinsey RL, Mackey AC, Walker ER, Frederick KE. Preparation, characterization, and in vitro efficacy of an acid-modified $\beta-\mathrm{TCP}$ material for dental hard-tissue remineralization. Acta Biomater. 2010;6:969-78.

13. Karlinsey RL, Pfarrer AM. Fluoride plus functionalized $\beta$-TCP: a promising combination for robust remineralization. Adv Dent Res. 2012;24:48-52.

14. Amaechi BT, Ramalingam K, Mensinksai PK, Narjibfard K, Mackey AC, Karlinsey RL. Remineralization of eroded enamel by a NaF rinse containing a novel calcium phosphate agent in an in situ model: a pilot study. Clin Cosmet Investig Dent. 2010;2:93100.

15. Han L, Edward CV, Li M, Niwano K, Neamat AB, Okamoto A, et al. Effect of fluoride mouth rinse on fluoride releasing and recharging from aesthetic dental materials. Dent Mater J. 2002;21: 285-95.

16. Fujimoto Y, Iwasa M, Murayama R, Miyazaki M, Nagafuji A, Nakatsuka T. Detection of ions released from S-PRG fillers and their modulation effect. Dent Mater J. 2010;29:392-7.

17. Itota T, Carrick TE, Yoshiyama M, McCabe JF. Fluoride release and recharge in giomer, compomer and resin composite. Dent Mater. 2004;20:789-95.

18. Ito S, Iijima M, Hashimoto M, Tsukamoto N, Mizoguchi I, Saito T. Effects of surface pre-reacted glass-ionomer fillerson mineral induction by phosphoprotein. J Dent. 2011;39:72-9.

19. Lynch E, Brauer DS, Karpukhina N, Gillam DG, Hill RG. Multicomponent bioactive glasses of varying fluoride content for treating dentin hypersensitivity. Dent Mater. 2012;28:168-78.

20. Wang ZJ, Sa Y, Sauro S, Chen H, Xing WZ, Ma X, et al. Effect of desensitising toothpastes on dentinal tubule occlusion: a dentine permeability measurement and SEM in vitro study. J Dent. 2010;38(5):400-10.

21. Mneimne $\mathrm{M}$ et al. High phosphate content significantly increases apatite formation of fluoride-containing bioactive glasses. Acta Biomater. 2011;7:1827-34.

22. Huang SB, Gao SS, Yu HY. Effect of nano-hydroxyapatite concentration on remineralization of initial enamel lesion. Biomed Mater. 2009;4:034104. doi:10.1088/1748-6041/4/3/034104.

23. Kim MY, Kwon HK, Choi CH, Kim BI. Combined effects of nanohydroxyapatite and $\mathrm{NaF}$ on remineralization of early caries lesion. Key Eng Mater. 2007;330-332:1347-50.

24. Najibfard K, Ramalingam K, Chedjieu I, Amaechi BT. Remineralization of early caries by nano-hydroxyapatite dentifrice. J Clin Dent. 2011;22(05):139-43. 
25. Kani K, Kani M, Isozaki A, Shintani H, Ohashi T, Tokumoto T. Effect of apatite-containing dentifrices on dental caries in school children. J Dent Health. 1989;19:104-9.

26. Rosenblatt A, Stamford TC, Niederman R. Silver diamine fluoride: a caries 'silver-fluoride bullet'. J Dent Res. 2009;88:116-25.

27. Yee R, Holmgren C, Mulder J, Lama D, Walker D, van Palenstein Helderman W. Efficacy of silver diamine fluoride for arresting caries treatment. J Dent Res. 2009;88:644-7.

28. Chu CH, Lo EC, Lin HC. Effectiveness of silver diamine fluoride and sodium fluoride varnish in arresting dentin caries in Chinese pre-school children. J Dent Res. 2002;81:767-70.

29. Cross KJ, Huq NL, Palamara JE, Perich JW, Reynolds EC. Physicochemical characterization of casein phosphopeptideamorphous calcium phosphate nanocomplexes. J Biol Chem. 2005;280:15362-9.

30. Cochrane NJ, Cai F, Huq NL, Burrow MF, Reynolds EC. New approaches to enhanced remineralization of tooth enamel. J Dent Res. 2010;89:1187-97.

31. Cochrane NJ, Saranathan S, Cai F, Cross KJ, Reynolds EC. Enamel subsurface lesion remineralisation with casein phosphopeptide stabilised solutions of calcium, phosphate and fluoride. Caries Res. 2008;42:88-97.

32. Cochrane NJ, Reynolds EC. Calcium phosphopeptides - mechanisms of action and evidence for clinical efficacy. Adv Dent Res 2012;24: 41-7.

33. Mainwaring PJ, Naylor MN. A four-year clinical study to determine the caries-inhibiting effect of calcium glycerophosphate and sodium fluoride in calcium carbonate base dentifrices containing sodium monofluorophosphate. Caries Res. 1983;17:267-76.

34. Lynch RJ. Calcium glycerophosphate and caries; a review of the literature. Int Dent J. 2004;54(5 Suppl 1):310-4.

35. Amaechi BT, Porteous N, Ramalingam K, Mensinkai PK, CcahuanaVasquez RA, Sadeghpour A, et al. Remineralization of artificial enamel lesions by Theobromine. Caries Res. 2013;47:399-405.

36. Nakamoto T, Simmons WB Jr, Falster AU. Apatite-FormingSystems: Methods and Products. US Patent application number: US 6,183,711 B1; 2001. http://patft.uspto.gov/netacgi/nphParser?Sect2=PTO1\&Sect2=HITOFF $\& p=1 \& u=/$ netahtml/PTO/searchbool.html\&r=1\&f=G\&l=50\&d=PALL\&RefSrch=yes\&Query=PN/ 6183711. 